\title{
Dragonfly-Artificial Neural Network Model for eLearning Data Analyses: Is Future Generation Communication Model Smart E-Learning System
}

\author{
Veeramanickam Murugappan ${ }^{1}$, Mohanapriya ${ }^{2}$, Bishwajeet Pandey $^{3}$, \\ Gajanan PArsalwad ${ }^{4}$, Senthil Kumar Janahan ${ }^{5}$ and MVigneshwar ${ }^{6}$ \\ ${ }^{1}$ PhD Scholar, Dept. of CSE, Karpagam University, Coimbatore, India \\ ${ }^{2}$ Professor \& Head, Dept. of CSE, Karpagam University, Coimbatore, India \\ ${ }^{3}$ Director, Gyancity Research Lab, India \\ ${ }^{4}$ Assistant Professor, Dept. of I.T, \\ Trinity College of Engineering \& Research, Pune, India \\ ${ }^{5}$ Assistant Professor, Dept. of CSE, Vels University, Pallavaram, Chennai, India \\ ${ }^{6}$ Assistant Professor, Dept. of CSE, Karpagam University, Coimbatore, India \\ ${ }^{1}$ manic.veera@gmail.com, ${ }^{2}$ mohanapriyaasaithambi@gmail.com, \\ 3yyancity@gyancity.com, ${ }^{4}$ gajanansggs@gmail.com, \\ ${ }^{5}$ senthil.jenahan@gmail.com, ${ }^{6}$ vignesh.manohar@gmail.com
}

\begin{abstract}
In this article, the importance of smart eLearning system with the neural network are suggested as future communication among varies entities which can be part of training and analysis of eLearning system students data in terms of qualitative outcomes among enormous definite datasets. In this direction, a proposed Dragonfly algorithm neural network (modified DA) model was established to predict student's marks in eLearning datasets for defines students' exams assessments examination results. The research study indicates that using modified DA model in evaluating and predicting students marks scoring patterns from dataset to figure out using neural network weight prediction factors of dragonfly behaviors of swarms particles analysis which bring to acquire complete results of data analyzed and hence predicted final results useful to every learner. The future generation smart e learning system most demanded feature in terms of integrating neural network learning system for eLearning applications in terms analyzing the dataset. This article enhances all features need in future for better communication and efficient smart eLearning system network.
\end{abstract}

Keywords: Smart eLearning system, artificial neural networks, Dragonfly Algorithms

\section{Introduction}

The artificial neural network used much more applications for modern technological aspects. So it's in need of the hours for a future generation eLearning communication system using various entities to fulfill demand in utilizing these modern concepts in learning and analyzing student's datasets. So we will look in further more detailed study of modified Dragonfly algorithms usage related to neural network features for efficient smart eLearning system. Data analysis is more in demand so role data scientist is in a peak near future. Especially in Machine learning platform, neural network and the future demand of industry are predicted to go beyond by higher than $50 \%$ by the year 2018. That's why perhaps as a good indication Harvard Business Review

Received (June 16, 2017), Review Result (August 23, 2017), Accepted (September 8, 2017) 
declared as data scientist to be the "sexiest" job in the 21 st century back in the year 2012.[1]

\section{Literature Study}

Smart eLearning model may have varies parameters to fulfill different methodology need to avail modern system design issues. This article listed out neural network importance with other three e-learning anatomy features. As ANNs are used to denote both linear \& nonlinear relationships, so basically ANN used in educational data analyses is more important to understand. Nurettin Yorek \& Ilker Ugulu (2015) states that "The ability to learn relationships directly from the data used, as detailed information on structures and interactions in the systems, Which is regarded as black-box models"[2] Rodrigo Siqueira-Batista(2014) stated "ANNs are computational systems with a mathematical-logic structure inspired in human neurophysiology"[3].

Data processing initiated with a learning level from a dataset-fluctuating in the weights of association among data in the network in a way that can be ANN reactions as similar as probably the results are detected in the training data.[4] As per Braga AP(2000) "It is expected that subsequently, the ANN acquires the ability to generalize, that is, the capability to furnish answers to previously unknown data"[5] As per Ramanathan L(2017) the selection features are given to Lion-Wolf NN for prediction of semester marks. Lion-Wolf Optimization algorithm is implemented to the training of neural network for finding optimal weight selection features. Experimentation of student performance prediction model was validated with training algorithm like GA, GWO, LION. [6] The educational application is featured with ANN is most anticipated design features for every in e-learning Application.

ANN layers are designed various technique here author listed importance of using MLP. In ANN Multilayer Perceptron is very popular architecture as in terms of

- As any number of inputs.

- As one or more than hidden neurons with varying number of units

- Uses sigmoid activation functions in hidden neuron layers.

- Have connections between input and output layers, between the hidden layers on the basis of last hidden layer and the output layer. [7] Sumam Sebastian(2015) it indicates the need for a variously hidden layer to predict best-fit output in NN.

As per author Boniecki $\mathrm{P}(2017)$ project design was developed as a very interactive computer systems which pursuant to software engineering learners will support an education in terms of field construction and operating with selected artificial neural network topologies model.[8] indicates that importance of $\mathrm{NN}$ in educational application systems. In this proposed system as per author Karan Manchandia(2017) perceptions to help in predicting the grades of the students and it will be most useful in terms of the user like faculty and student which evaluate the student's academic datasets in a better way with less error while doing classification of grades without human errors [9].

Francis T. S. Yu states that "An innovative education is reliant on the subject area that users are learning. For that need more memorization for learning, the user would use smart associative learning." [10] Smart Learning can be in term of Associative, Cognitive, and Creative are remembering, understanding and thinking based learning accordingly. So learning is needed to modernize according to learner capabilities and skill oriented features [10]. 


\section{Smart E-learning System}

As technological advance happening daily basis so it's very important to utilize in any eLearning which becomes smart ELearning system if it can avail the latest technology to itself. Any e-learning application must adopt maximum features in term of better communication among all entities. So system features are capable of synchronize with class room teachings using IoT networking entities, gamification based tutoring and notes with modern terms, social networking concept in designing application to efficient sharing among all users, finally current trends and importance of using neural network for analyzing students datasets with most best fit prediction model to use in it. We analyze all the best features any smart eLearning system must have: such as

1. SNS in eLearning Application (Social Networking Service)[11]

2. GAMIFICATION eLearning System [12]

3. SMART I- CAMPUS (using IOT in eLearning system) [14]

4. Modified DA-Artificial Neural Network Model: Is Future Generation Smart System

\subsection{SNS in eLearning Application (Social Networking Service)}

As per author Veeramanickam(2014) "Social networking based e learning system can be used to support the emergence of E-learning with Cloud networking system. Usually, different from the normal web based e learning application, So Social learning is competent of continuous, seamless accessing, allows the system to acquire the e learning text subject notes from the huge number of user in the real world smart system"[11].

Two different features for SNS based system in terms of "E-Learning to Social Networks and Social Networks to E-Learning" As SL more efficient to bring more outcomes to smart system in achieving various listed one, such as Learning Outcomes

Social Learning Application: SNS in E-learning application

- User Account creation

- Authentication of Users

- Making Groups

- Supervision of all groups

- Group Members Communication

- Sharing within User

- Subjects Services

- Learn and Share

- Assessment of student's users

- Content Management

- Publishing E-learning Notes

- Tracking Users Activities [11]

\subsection{Gamification eLearning System}

Educational games give us the additional knowledge to the learners through designed with the educational subject's task. [12] As author Veeramanickam(2014) states that "As its application design for educating the student's learners to the certain subjects, using supporting us in terms of educating a skill as while play games help to learn new things in acquiring new knowledge. "Most popular entertainment medium is computer games throughout the world"[12]. Most of Gamification model support in terms of 5 factors to design \& apply in perfect features. 
- "Resources subjects

- New Innovative Syllabus

- Support Model System

- New Technology

- Assessments Evaluation"[12]

It's great impact to e-learning system related to various perspectives such as psychology, HCI, AI, Design factors, Development of application issues \& instructional features in e-learning.

"What Research Says About Game-Based Learning

- How much is new research finding avail to confirm the outcomes from learning?

- In What scenario to use evidence-centered features to create newly gamesassessments

- How to validate new assessment tools utilized.

- How to measure users learning outcomes this games based application. "[13]

\subsection{SMART I- CAMPUS (using IoT in eLearning System)}

Technology advances as Sensors are used in every device nowadays. Our Traditional classrooms must be modernized to current scenario in using sensors related devices in terms of IoT for excellent infrastructure to normal campus can be SMART-I Campus. Veeramanickam(2016) states that "IoT enabled classrooms in which data collection can be possible by using devices for E-Learning application."[14]

\section{SMART I- CAMPUS}

"Smart Campus as combination of many smart things collectively in single system as listed below

- Smart E-learning-IOT

- IOT empowered Classroom

- IOT empowered Laboratory

- Sensor integrated Notes Sharing

- Sensor with Mobiles Apps.

- IOT empowered Hotspot - I-Campus"[14]

Future "Futurus" IOT Campus will provide various services in smart campus accessible in handheld devices by doing ideal connectivity among multiple things to integrate E-learning for academics."[14] Stephanie Ivec(2015) states that "The IoT doesn't function without cloud integrates applications to understand and transfer the data generated from every sensor."[15] Any Smart classroom is always towards the user centric methods which will carry forward student's notes to next higher level through the source collected from the IOT devices. Dlodlo N(2012) States that "The development of the Internet of Things is estimated to come with a new sort of usercentric based services to users, besides on the interface of daily processes with the network entity."[16] 


\subsection{Dragonfly-Artificial Neural Network Model: Is Future Generation Smart System}

This research article completely studied and implemented Neural Network system for educational data analyses using Dragonfly Algorithms and novelty in proposed features as modified dragonfly algorithms to predict best-fit results by analyzing student's datasets and learning scoring patterns of student's user's marks as fourth features in Smart E-learning System Model.

\section{Artificial Neural Networks}

Biological neural system features are resembled to reflect it in artificial neural networks (ANNs) using mathematical formulae like in human brain system.

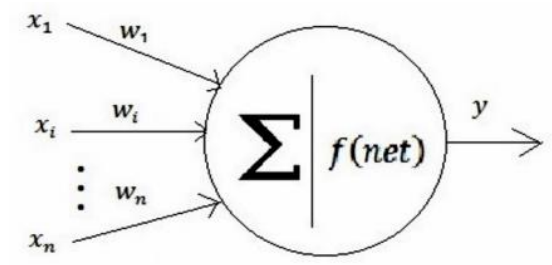

Figure 1. Representation of Single Neuron in ANN[17]

As Figure 1 represents as single artificial neurons in terms of the biological system were first described by McCulloch and Pitts. McCulloch-Pitts. Results summation of a single unit as given in the formulae as any input multiplied with corresponding weights factors connection. All weights summed up to produce net output for every single unit neuron.

$\mathrm{Net}=\mathrm{W}_{1} \mathrm{X}_{1}+\mathrm{W}_{2} \mathrm{X}_{2}+\ldots .+\mathrm{W}_{\mathrm{n}} \mathrm{X}_{\mathrm{n}}+\mathrm{X}_{0} \mathrm{~b}$

$\mathrm{Y}=f\left(\right.$ net) $\mathrm{X}_{\mathrm{i}}-$ input values, $\mathrm{W}_{\mathrm{i}}$-connection weights

As Rodrigo Siqueira-Batista(2014) states that Either single layer or multilayer ANN structure are used to deploy NN system and classified based on the number of layers used for $\mathrm{NN}[17]$.

\subsection{Neural Network Design: FNN}

The Artificial neural network design intends to analyses students' dataset for to predict of final semester results based scoring patterns given data inputs of engineering students semester marks.

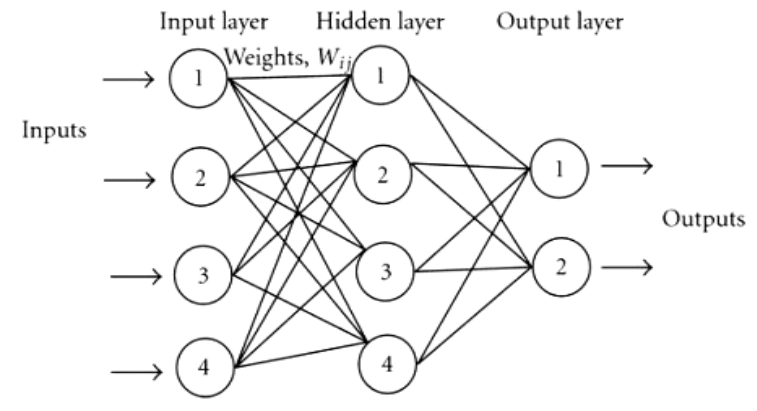

Figure 2. Representation of Feedforward NN 
Feedforward neural networks are a very traditional forward technique, as the practical NN network which as four input neuron cells and two output neuron cell, as the model is designed to depict simple logic of FNN in Figure 2. Learning is an essential process of any NN. As Nurettin Yorek \& Ilker(2015) "this system trains using back-propagation technique so-called supervised learning. As it assumed as that $\mathrm{NN}$ has enough number of hidden layers level, as it each time models it can connect between the input and output levels."[18]

\subsection{The Simple Process of Training an FNN is as Follows:}

As per Karan Manchandia \& Navdeep Khare(2017), i) Input data is passing on and propagated in the network till it attains output layer. As it forward technique producing predict results. ii)The produced output is always deducted from the past actual output \& error values are calculated in the NN. iii)This is exactly supervised learning, as in back propagation methods too, Its learning method to adjust the weights in NN. iv)Since it completes it back propagation, the once again forward process it starts, \& this is repeated cycle till it can able to figure out minimum error among the predicted and actual outputs in NN[9]

\section{Dragonfly Algorithm -DA}

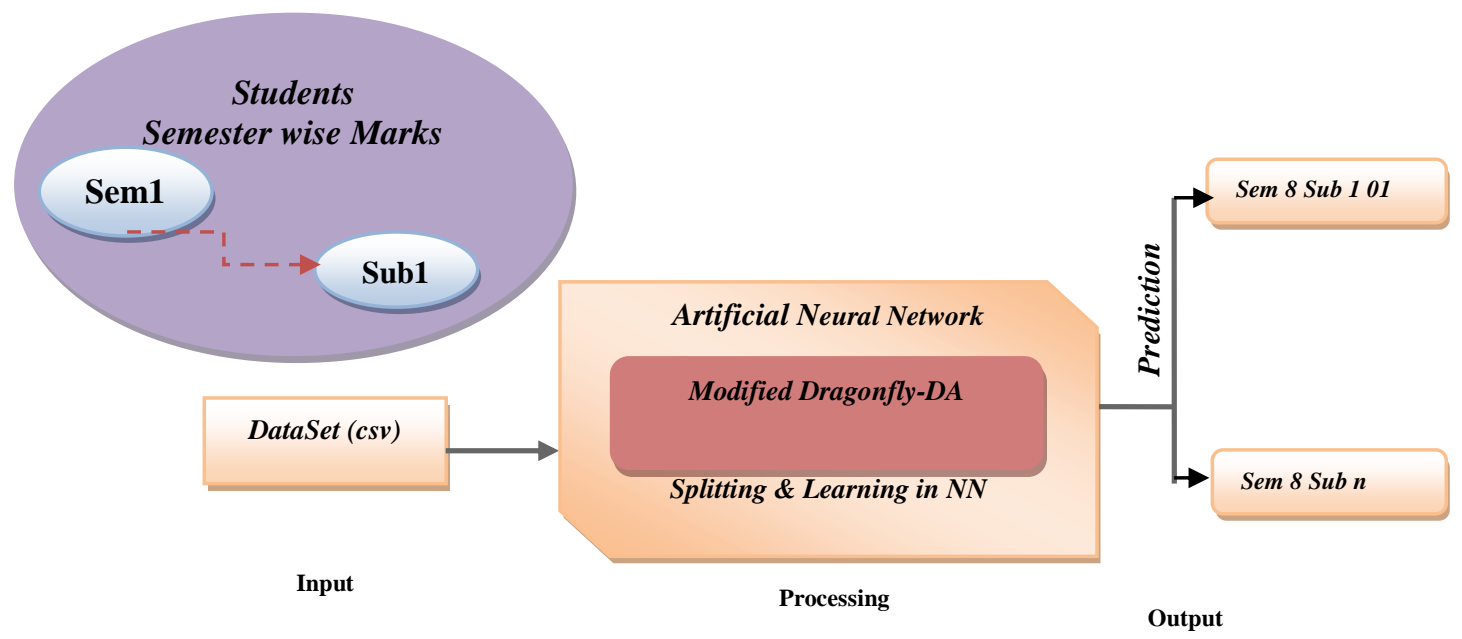

Figure 3. Architecture of E-learning Data Analyses

Students Dataset (semester wise subjects) as input to NN for analyzing data with back propagation learning to train the system, Dragonfly algorithms predict the best fit using swarms particles and its behaviors of searching food sources and outwards for the enemies' similar manner data prediction system going to learn and predict. A collection of all subjects marks from the semester as represented in Figure 3. Training data are separated from actual data to train $\mathrm{NN}$ on the basis of learning system under supervised learning system. 

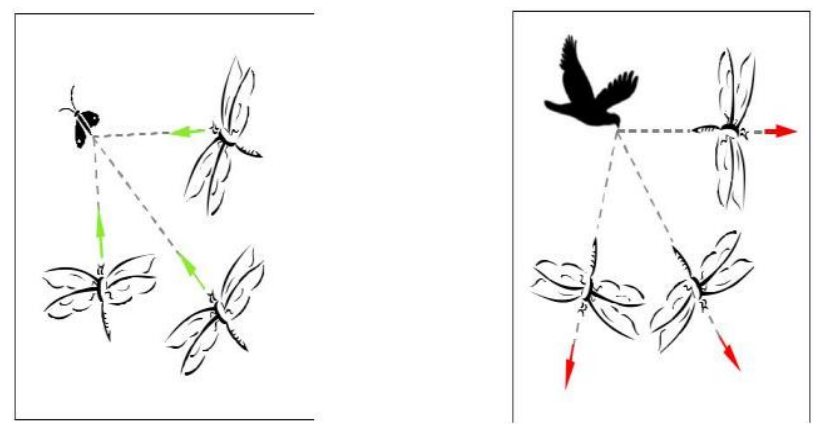

\section{Figure 4. Primitive Behaviors Patterns in Dragonflies Swarm [19]}

Figure 4 represents the dragonfly tendency towards food, outward to enemies [19] As per Reynolds, the swarm behaviors of the dragonfly are three primitive [20]:

- "Separation, in the swarm NN.

- Alignment, on the basis velocity matching of individuals in NN.

- Cohesion, as the tendency of swarms towards mass in NN."[20]

\subsection{Dragonfly Algorithm pseudo-codes are:}

Modified Dragonfly used to predict better learning of students marks prediction, as modified value chosen from the last three cycle's weights prediction learning to produce a better best-fit prediction. "Modified Dragonfly algorithm using the modified 3.6 Equations from DA algorithm" [19] Seyedali Mirjalili(2016) states that "In step by step procedure of DA pseudo code. So new features using memories of old prediction weights factor taken into account, to sum up, Bi limits is to find out new velocity vector as per the procedure of Dragonfly."[19]

"Step1: The dragonflies population Initialized for $\mathrm{X}_{\mathrm{i}}(\mathrm{i}=1,2 \ldots \mathrm{n})$

Step: $2 \Delta \mathrm{Xi}$ is Initialized step vectors value $(\mathrm{i}=1, \ldots \mathrm{n})$

Whenever end condition is not satisfied

Step: 3 Every Swarm value to be computed.

Step: 4 On basis of food \& enemy are updated.

Step: 5 Values of w, s, a, c, f, \& e to be calculated.

Step: 6 To Calculate primitive patterns using S, A, C, F, \& E by using Eqs. (3.1) to (3.5).[19]

Step: 7 while any one adjacent dragonfly is accessible -update their radius.

Step: 8 Velocity vector is updated by using Eq. (3.6)[19] As mentioned below.

Step: 9 New position vector is to be updated using Eq. (3.7)[19]

$$
X_{t+1}=X_{t}+\Delta X_{t+1}
$$

Else

New position vector is to be updated using Eq. (3.8)[19]

$$
X_{t+1}=X_{t}+\operatorname{Lévy}(d) \times X_{t}
$$

End if

Step: 10 new boundaries are figured out to new positions correctly as per listed above 
variables patterns.

End while" [19]

$$
\Delta X_{t+1}=(s S i+a A i+c C i+f F i+e E i)+w \Delta X t \text { (3.6) Equation[19] }
$$

Whereas added new velocity factor in this existing DA position vector formulae as adding $\Delta \mathrm{Xt}$ with old cycles values from memory of best prediction in this combination to figure out the best vector among current prediction with old previous prediction results to improve its efficiency in the velocity vector of DA becomes modified DA novelty work. Rest of factors S,A,C,F,E remains same five behavioral patterns of swarm's optimization with a newly added average of $X_{t}$ with others factor in DA methods. [19] Learning of this training and prediction is repeated processes until satisfying condition reaches. So mean squared error -MSE is finding deviations in predicted results of every unit with expected output as per training algorithm's and velocity position vectors factors.

Single-Objective using DA optimization methods are utilized to figure out values of $\mathrm{X}$ and $\Delta \mathrm{X}$ vectors in the optimization procedure. As lower \& upper boundaries of every swarm in the NN are defined limitations to predict new results in NN. Every iteration pseudo of DA procedure is followed only modification in finding a new position using modified weights factors in modified DA method processes. Seyedali Mirjalili(2016) states that "For updating, an adjunct for every dragonfly are chosen based on a calculation of Euclidean distance formulae among other swarms in the $\mathrm{NN}$ and selection $\mathrm{N}$ of among them."[19] This is repeated activities till end condition are satisfied.

\section{Implementation}

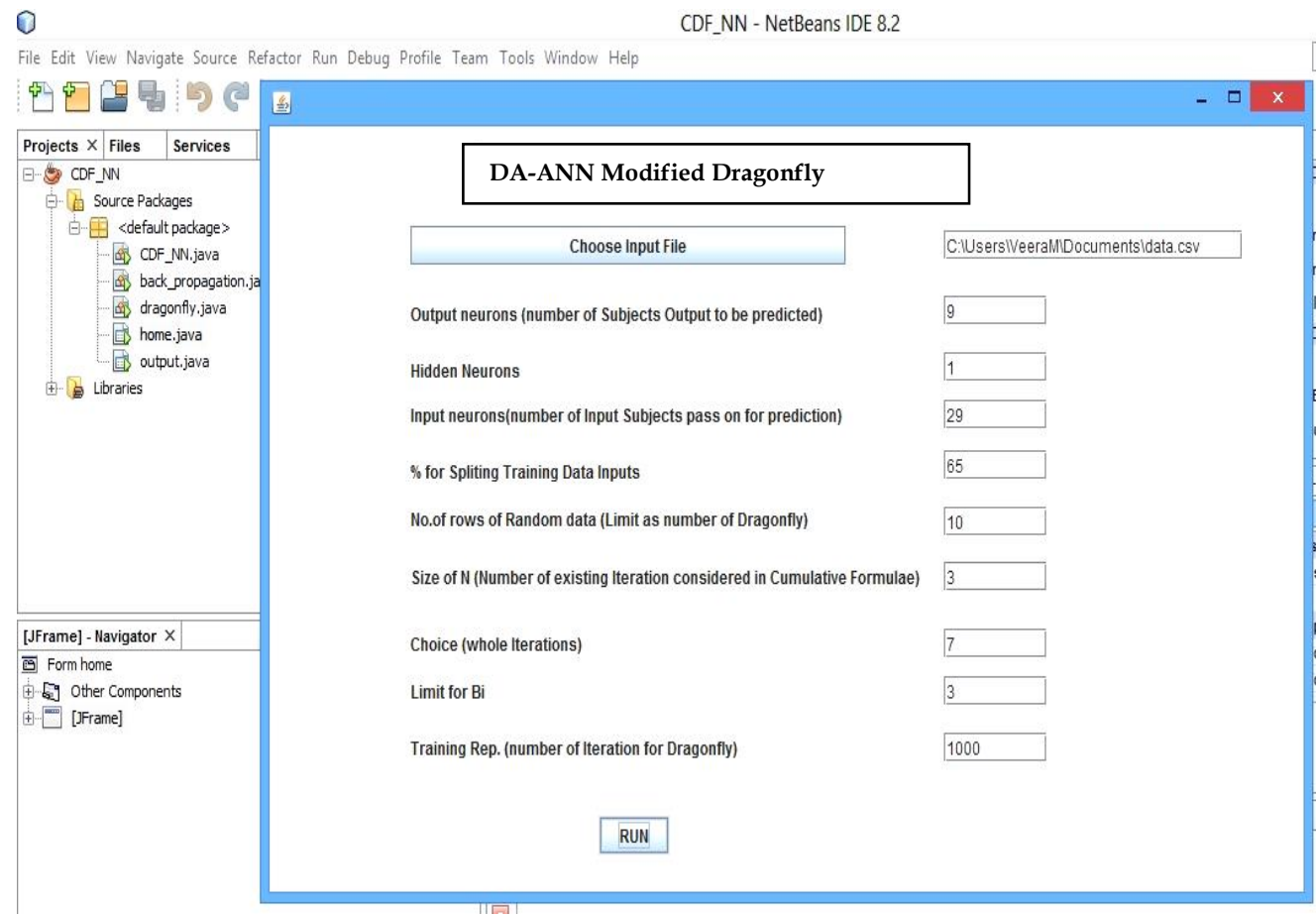

Figure 5. Modified DA Implementation using Java Platform

As per Figure 5 is a screenshot for java implementation of modified DA algorithms to analysis student's dataset for best-fit perdition results to learning marks scoring patterns using modified DA-NN for smart e-learning system. 


\section{Results Predict}

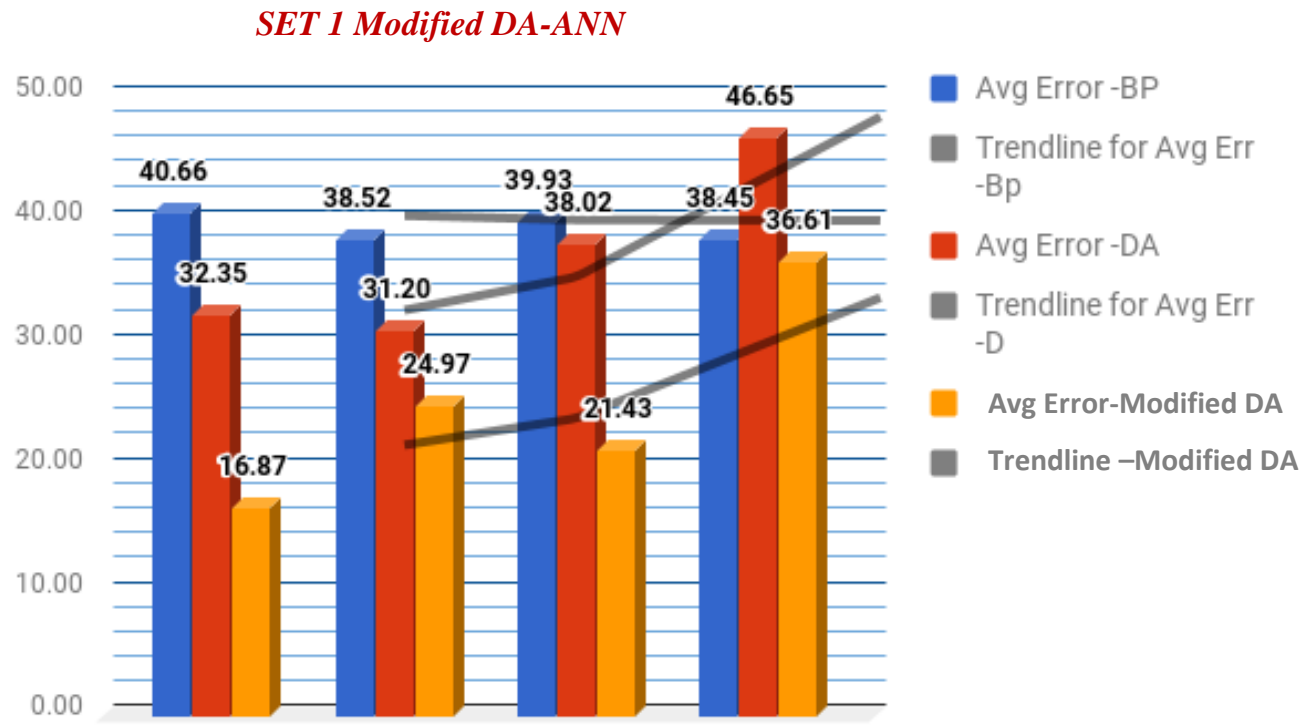

Figure 6. Modified DA Results

Table 1a. Set 01 Modified DA Results

\begin{tabular}{|c|c|c|c|c|c|c|c|c|}
\hline $\begin{array}{c}\text { Output } \\
\text { neurons (no: } \\
\text { of subjects } \\
\text { to be } \\
\text { predicted) }\end{array}$ & $\begin{array}{c}\text { Hidden } \\
\text { neurons } \\
\text { any no:) }\end{array}$ & $\begin{array}{c}\text { Input } \\
\text { neurons(no: of } \\
\text { input subjects } \\
\text { to be } \\
\text { predicted) }\end{array}$ & $\begin{array}{c}\text { percentage } \\
\text { (TRAINING } \\
\text { DATA \% to } \\
90\end{array}$ & $\begin{array}{c}\text { Limit (no: } \\
\text { of } \\
\text { dragonfly) }\end{array}$ & $\begin{array}{c}\text { N size (No: } \\
\text { of existing } \\
\text { iteration } \\
\text { consider for } \\
\text { modified } \\
\text { formula) }\end{array}$ & $\begin{array}{c}\text { Limit } \\
\text { choice } \\
\text { (whole } \\
\text { iterations) }\end{array}$ & $\begin{array}{c}\text { Training reps } \\
\text { iteration the } \\
\text { modified } \\
\text { formula as } \\
\text { consider) }\end{array}$ & $\begin{array}{c}\text { (neration for } \\
\text { dragonfly) } \\
\text { less than } \\
5000\end{array}$ \\
\hline 9 & 1 & 29 & 70 & 10 & 3 & 7 & 3 & 100 \\
\hline 9 & 20 & 29 & 90 & 10 & 3 & 7 & 3 & 100 \\
\hline 9 & 40 & 29 & 40 & 10 & 3 & 7 & 3 & 100 \\
\hline 9 & 100 & 29 & 20 & 10 & 3 & 7 & 3 & 100 \\
\hline
\end{tabular}

Table 1b. Set 01 Modified DA Results

\begin{tabular}{|c|c|c|c|c|c|}
\hline Avg Err-Bp & $\begin{array}{c}\text { Sqrt avg Err- } \\
\text { Bp }\end{array}$ & Avg Err-DA & $\begin{array}{c}\text { Sqrt avg Err- } \\
\text { DA }\end{array}$ & $\begin{array}{c}\text { Avg Err - } \\
\text { modified DA }\end{array}$ & $\begin{array}{c}\text { Sqrt avg Err - } \\
\text { modified DA }\end{array}$ \\
\hline 40.66 & 6.38 & 32.35 & 5.69 & $\mathbf{1 6 . 8 7}$ & 4.11 \\
\hline 38.52 & 6.21 & 31.20 & 5.59 & 24.97 & 5.00 \\
\hline 39.93 & 6.32 & 38.02 & 6.17 & 21.43 & 4.63 \\
\hline 38.45 & 6.20 & 46.65 & 6.83 & 36.61 & 6.05 \\
\hline
\end{tabular}

Totally 08 experimentation analysis is carried out to using students datasets. SET 01, 02 are displayed on tabulation $1 \mathrm{a}, 1 \mathrm{~b}$ and as figure 6 show trends line indicates variation in predicted outputs. Among 3 optimization results, modified DA produces the best results with lowest MSE values in the NN. 


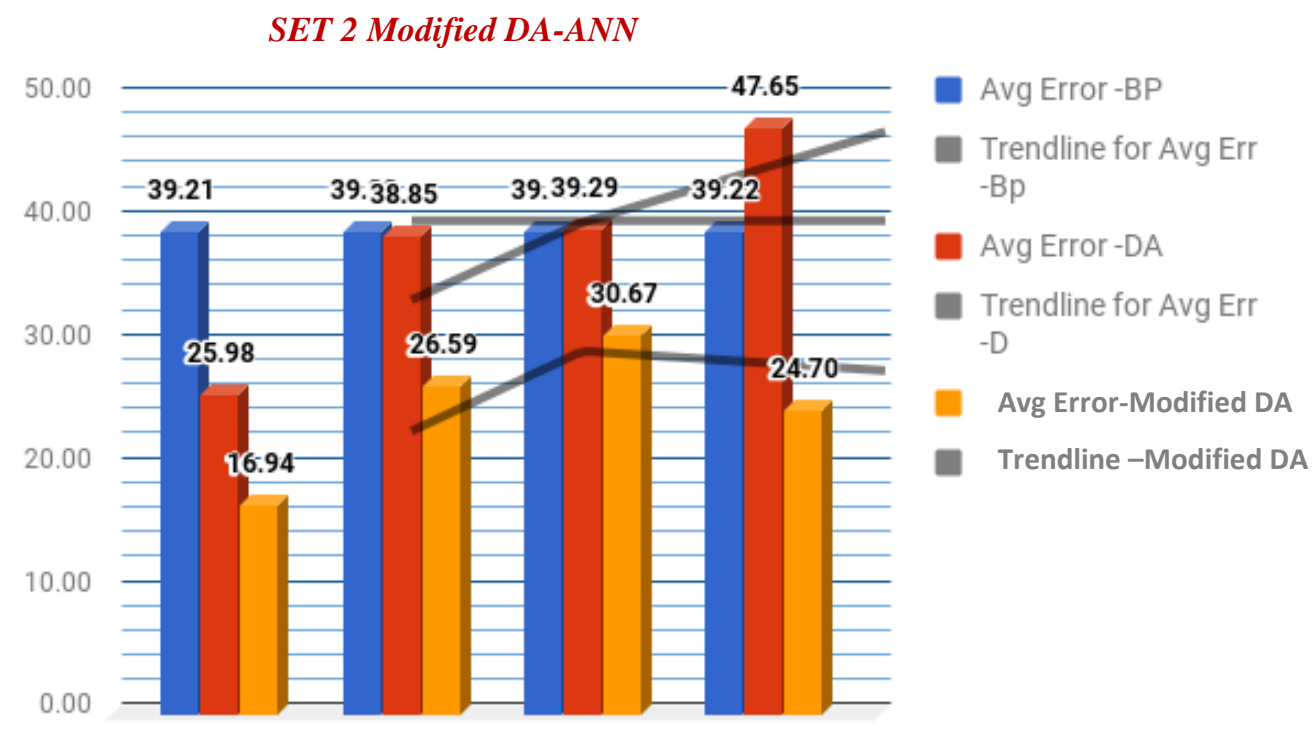

Figure 7. Modified DA Results

Table 2a. Set 02 Modified DA Results

\begin{tabular}{|c|c|c|c|c|c|c|c|c|}
\hline $\begin{array}{c}\text { Output } \\
\text { neurons (no: } \\
\text { of subjects to } \\
\text { be predicted) }\end{array}$ & $\begin{array}{c}\text { Hidden } \\
\text { neurons } \\
\text { any no:) }\end{array}$ & $\begin{array}{c}\text { Input } \\
\text { neurons(no: of } \\
\text { input subjects } \\
\text { to be predicted) }\end{array}$ & $\begin{array}{c}\text { percentage } \\
\text { (TRAINING } \\
\text { DATA \% 10 to } \\
90\end{array}$ & $\begin{array}{c}\text { Limit (no: } \\
\text { of } \\
\text { dragonfly) }\end{array}$ & $\begin{array}{c}\text { size (No: of } \\
\text { existing } \\
\text { iteration } \\
\text { consider for } \\
\text { modified } \\
\text { formula) }\end{array}$ & $\begin{array}{c}\text { (whole } \\
\text { choice } \\
\text { iterations) }\end{array}$ & $\begin{array}{c}\text { limit (from } \\
\text { no: iteration } \\
\text { the modified } \\
\text { formula as } \\
\text { consider) }\end{array}$ & $\begin{array}{c}\text { Training reps } \\
\text { (number of } \\
\text { iteration for } \\
\text { dragonfly) less } \\
\text { than 5000 }\end{array}$ \\
\hline 9 & 1 & 29 & 50 & 10 & 3 & 7 & 3 & 500 \\
\hline 9 & 20 & 29 & 50 & 10 & 3 & 7 & 3 & 1000 \\
\hline 9 & 40 & 29 & 50 & 10 & 3 & 7 & 3 & 2500 \\
\hline 9 & 100 & 29 & 50 & 10 & 3 & 7 & 3 & 5000 \\
\hline
\end{tabular}

Table 2b. Set 02 Modified DA Results

\begin{tabular}{|c|c|c|c|c|c|}
\hline Avg Err-Bp & $\begin{array}{c}\text { Sqrt avg Err- } \\
\text { Bp }\end{array}$ & Avg Err-DA & $\begin{array}{c}\text { Sqrt avg Err- } \\
\text { DA }\end{array}$ & $\begin{array}{c}\text { Avg Err - } \\
\text { modified } \\
\text { DA }\end{array}$ & $\begin{array}{c}\text { Sqrt avg Err- } \\
\text { modified DA }\end{array}$ \\
\hline 39.21 & 6.26 & 25.98 & 5.10 & $\mathbf{1 6 . 9 4}$ & 4.12 \\
\hline 39.22 & 6.26 & 38.85 & 6.23 & 26.59 & 5.16 \\
\hline 39.22 & 6.26 & 39.29 & 6.27 & 30.67 & 5.54 \\
\hline 39.22 & 6.26 & 47.65 & 6.90 & 24.70 & 4.97 \\
\hline
\end{tabular}

All 08 experimentation analyses are carried out to using various inputs in terms hidden layers, the percentage of training data inputs, the number of training representation. SET 01, 02 from Table 2a,2b are displayed with $16.87 \& 16.94$ in MSE as best results among all 8 experimental study results of Modified DA with lowest MSE values in the NN. The graph displayed in Figure 7 for Set2. 

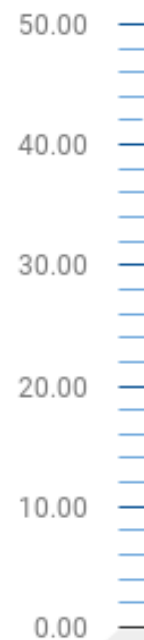

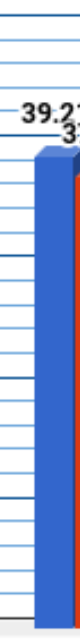

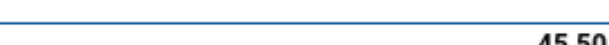

45.50

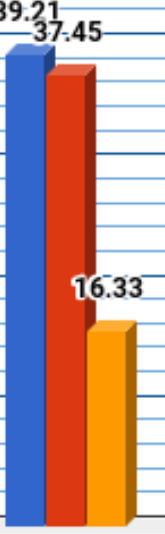

$-39.44-39.44$

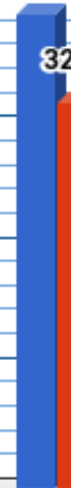

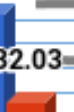

03
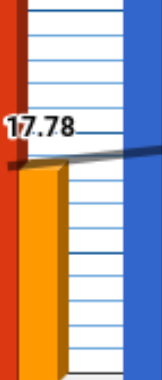
0
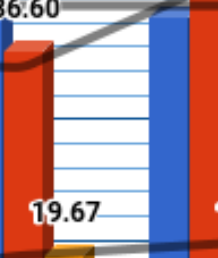

.
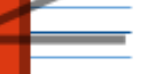

(1)

3

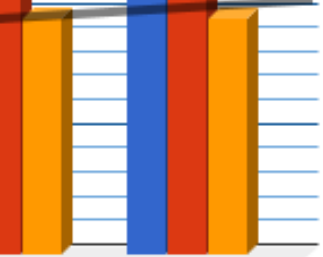

40
Avg Error -BP

Trendline for Avg Err -Bp

Avg Error -DA

Trendline for Avg Err $-\mathrm{D}$

Avg Error-Modified DA

Trendline-Modified DA

Figure 8. Hidden Layers - Modified DA Results

Table 3. Hidden Layers -Modified DA Results

\begin{tabular}{|c|c|c|c|}
\hline $\begin{array}{c}\text { Hidden Layers } \\
\text { (no: of layers) }\end{array}$ & Avg Error -BP & Avg Error -DA & Avg Error - modified DA \\
\hline 1 & 39.21 & 37.45 & $\mathbf{1 6 . 3 3}$ \\
\hline 3 & 39.44 & 32.03 & 17.78 \\
\hline 12 & 39.44 & 36.60 & 19.67 \\
\hline 40 & 39.44 & 45.50 & 19.61 \\
\hline
\end{tabular}

All Data with SET 01,02 displayed with varying in hidden layers as per Graph in Figure 8.

\section{Future Scope}

As any NN learning purely basis on the best dataset. To be more specific with multiple objective features as data inputs using DA and Modified DA can enhance betterment of higher learning rate in the academic dataset.

\section{Conclusion}

Smart eLearning system functionalities four design technique are featured in this article. As describe the importance of e-learning up to date with technological advancement in Computer domain platform. Educational system dataset is focused only in terms of mining till date but for future Neural Network importance in huge ultimatum on analysis academic data's pattern and behaviors on the basis learning data with supervised learning to figure out predictable outcomes on various circumstances relevant to dataset features. In Modified DA Neural Network works as implemented and student's datasets are analyzed on predicting scoring patterns of examinations assessments. As predicted MSE with Modified DA results are best among DA and BP-back prorogation methods with lowest values indicated in tabulation with graph \& trend line. Any eLearning 
applications as of now need of ANN design features to learn datasets features behaviors and analysis it to utilize in the better improvement field of Academic teaching and learning processes.

\section{References}

[1] Machine Learning Is Creating A Demand for New Skills" www.forbes.com/sites/forbestechcouncil/2017/06/26/machine-learning-is-creating-a-demand-for-newskills/\#325004dc7ae2 by Hovhannes Avoyan.

[2] N. Yorek and I. Ugulu, "Educational Research and Reviews", Article Number: 4E694F455430 ISSN 1990-3839, vol. 10, no. 18, (2015) September 23, pp. 2606-2616.

[3] R. Siqueira-Batista and R. Roger Vitorino, "Artificial neural networks and the teaching of edicine", Brazilian Journal of Medical Education, ISSN 0100-5502, Http://dx.doi.org/10.1590/S010055022014000400017.

[4] Artificial Neural Networks and medical Education as redes Neurais artificial e o Ensino da medicine Rodrigo Siqueira-BatistaI Rodrigo Roger Vitorino, Brazilian Journal of Medical Education, ISSN 01005502, vol. 38, no. 4, (2014), pp. 557-565.

[5] A. P. Braga, A. P. L. F. Carvalho, T. B. Ludermir, "Redes Neurais Artificiais: Teoria e aplicações", Rio de Janeiro: LTC; (2000).

[6] L. Ramanathan, A. Geetha, M. Khalid and P. Swarnalatha, "Student Performance Prediction Model Based on Lion-Wolf Neural Network", International Journal of Intelligent Engineering and Systems, vol. 10, no. 1, (2017).

[7] S. Sebastian and J. J. Puthiyidam, "Evaluating Students Performance by Artificial Neural Network using WEKA", International Journal of Computer Applications (0975 - 8887), vol. 119, no. 23, (2015) June.

[8] P. Boniecki, J. Weres, A. Krysztofiak and W. Mueller, "Interactive education system supporting the use of artificial neural networks in agriculture engineering", retrieved on 13 July 2017 from http://www.efita.net/apps/accesbase/bindocload.asp?d=6326\&t=0\&identobj=80U2W13p\&uid=5730529 $0 \&$ sid $=57 \& \mathrm{idk}=1$.

[9] Implementation of Student Performance Evaluation Through Supervised Learning Using Neural Network, Karan Manchandia, Navdeep Khare DOI: 10.5281/zenodo.438101 ISSN: 2277-9655, IJERST, vol. 6 , no. 3, (2017) March.

[10] "Neural Networks \& Education: The Art of Learning" by Francis T. S. Yu http://esc.kuas.edu.tw/ashx/DataTrans.ashx?guid=0ee35e84-30ab-4fcb-90f7-ce61a1638682

[11] M. R. M. Veeramanickam and N. Radhika, "A Smart E-Learning System for Social Networking", International Journal of Electrical and Computer Engineering (IJECE), ISSN: 2088-8708, vol. 4, no. 3, (2014) June, pp. 447-455.

[12] M. R. M. Veeramanickam and N. Radhika, "A Study on Educational Games Application Model in ELearning Cloud System”, ICICES2014, ISBN No.978-1-4799-3834-6/14/\$31.00@2014 IEEE.

[13] "What Research Says About Game-Based Learning (Research on Assessment in Games) "by EDSURGE ARTICLE Aug 20, 2013, retrieved on 13 July from www.edsurge.com.

[14] M. R. M. Veeramanickam and Dr. M. Mohanapriya, "IOT enabled Futurus Smart Campus with effective E-Learning: i-Campus", GSTF Journal of Engineering Technology (JET), DOI: 10.5176/22513701_3.4.164, vol. 3, no. 4, (2016) April.

[15] http://trivantis.com/blog/elearning-internet-things titled as "eLearning and the Internet of Things" By Stephanie Ivec published on August 4, 2015, data retrieved on 20th Nov 2015.

[16] N. Dlodlo, T. Foko, P. Mvelase and S. Mathaba, "The State of Affairs in Internet of Things Research", The Electronic Journal Information Systems Evaluation, available online at www.ejise.com, vol. 15, no. 3, (2012), pp. 244-258.

[17] e o Ensino da medicina R. Siqueira-Batista and R. Roger Vitorino, "Artificial Neural Networks and medical Education as redes Neurais artificiais”, Revista BRasileiRa de educação Médica., vol. 38, no. 4, (2014), pp. 557-565.

[18] I. Nurettin Yorek, "A CFBPN artificial neural network model for educational qualitative data analyses: Example of students' attitudes based on Kellerts' typologies”, Educational Research and Reviews, DOI: 10.5897/ERR2015.2370 Article Number: 4E694F455430 ISSN 1990-3839, retrieved from http://www.academicjournals.org/ERR, vol. 10, no. 18, (2015) September 23, pp. 2606-2616.

[19] S. Mirjalili, "Dragonfly algorithm: a new meta-heuristic optimization technique for solving singleobjective, discrete, and multi-objective problems", Neural Computing and Applications, vol. 27, no. 4, (2016) May, pp. 1053-1073.

[20] Reynolds CW (1987) Flocks, herds, and schools: a distributed behavioral model. ACM SIGGRAPH Comput Gr 21:25-34. 